Running Head: INTERGROUP CONTACT AND COVID-19 DISCRIMINATION

Can past intergroup contact shape support for policies in a pandemic? Processes predicting endorsement of discriminatory Chinese restrictions during the COVID-19 crisis 


\begin{abstract}
A survey of 340 British residents was conducted when COVID-19 virus first reached the UK in February 2020. We measured past experiences of positive and negative intergroup contact with Chinese people as predictors of intergroup threat and emotions in the context of the pandemic; and how these processes in turn predicted support for discriminatory policies designed to restrict the freedom of Chinese people in the UK. We tested a novel threatmatching hypothesis which draws upon models of outgroup-specific social perception to predict that the emotional processes underlying contact effects will depend on the specific threat posed by the outgroup. In the present epidemiological context, Chinese people posed a salient threat to individuals' physical health and welfare. Accordingly, we show that whilst intergroup contact predicted both fear and anger towards the outgroup, the indirect effect of contact on support for Chinese restriction policies via fear was significantly stronger than the indirect effect via anger. Our findings provide a more nuanced understanding of how specific threat and emotions drive intergroup contact effects, and offer important insights for efforts to maintain positive intergroup relations in the face of the crisis.
\end{abstract}

Keywords: COVID-19; INTERGROUP CONTACT; INTERGROUP EMOTIONS; THREAT; INTERGROUP RELATIONS; PREJUDICE 


\section{Can past intergroup contact shape support for policies in a pandemic? Processes predicting endorsement of discriminatory Chinese restrictions during the \\ COVID-19 crisis}

In December 2019, an outbreak of viral pneumonia was detected in China caused by a novel coronavirus, SARS-CoV-2 (COVID-19). At the time this research was conducted, 50,000 cases of laboratory-confirmed COVID-19 had been detected in China, and the virus had begun to spread beyond its origin with a further 1,200 confirmed cases across 26 countries, including nine in the United Kingdom (WHO, 2020). The British Foreign and Commonwealth Office advised against all but essential travel to mainland China but most British lives were uninterrupted. Nevertheless, opinion polls suggested that one in three Brits already saw the virus as a moderate to high personal threat (Quigley, 2020). In all countries except for China the source of the disease was foreign. The spread of the virus between nations poses a fundamentally intergroup challenge, requiring cross-national understanding and cooperation. This research draws on classic social-psychological theorising to explore how prior intergroup contact predicts prejudice and discrimination in light of the crisis, focusing on the role of threat-specific intergroup emotions in this process.

Intergroup contact theory has been one of the most influential theories in social psychology since it was first formulated by Gordon Allport in 1954. The theory states that interactions between people from different ethnic, cultural and social backgrounds are key to reducing prejudice and discrimination. Extensive evidence, including multiple meta-analyses, demonstrate that positive contact is effective in reducing prejudice towards a broad range of stigmatized outgroups (Davies, 2011; Lemmer \& Wagner, 2015; Pettigrew \& Tropp, 2006). More recently, research has shown that while positive contact reduces prejudice, negative contact predicts more negative outgroup beliefs and attitudes (e.g. Barlow et al., 2012, Graf, Paolini, \& Rubin, 2014; Paolini et al., 2010). 
Intergroup contact research has typically measured peoples' generalized liking and disliking for the outgroup as the primary outcome variable (Pettigrew \& Tropp, 2011; Stark et al., 2013). This broad focus on prejudice-as-general-attitude potentially conceals a wide range of discrete and functionally distinct emotions felt towards outgroups. Researchers from intergroup emotion traditions have demonstrated that bias towards outgroups can manifest as different emotions (e.g. anger, fear, disgust, pity, guilt) and these emotions direct and regulate different intergroup behaviours (e.g. Cottrell \& Neuberg, 2005; Fiske et al., 2002; Mackie \& Smith, 2018). Exploring the emotional consequences of intergroup contact would therefore allow us not only to assess evaluative valence, but also to predict a range of different behavioural reactions to the outgroup (e.g. approach and affiliation, confrontation and attack, or avoidance and separation).

Some recent work has begun to explore the impact of intergroup contact on discrete intergroup emotions. For instance, Seger and colleagues (2017) found that positive contact was associated with both a decrease in negative emotions (i.e. anger, disgust) and an increase in positive emotions (i.e. admiration) towards the outgroup. Kauff et al., (2017) found that both positive and negative contact were associated with specific positive and negative intergroup emotions (i.e. anger, fear, and happiness). Most recently, Barlow et al., (2019) found evidence in support of their affect matching hypothesis whereby positive contact experiences have a disproportionately strong relationship with positive intergroup emotions, whereas negative contact experiences have a disproportionally strong association with negative intergroup emotions.

In this paper we further explore the specific emotional consequences of positive and negative intergroup contact within the context of the COVID-19 pandemic. According to the sociofunctional model of intergroup affect (for overviews, see Cottrell \& Neuberg, 2005; Neuberg \& Cottrell, 2002) the specific emotions felt towards outgroups are determined by the 
specific threat the outgroup represents to the ingroup. A key distinction can be drawn between physical threats and threats directed at valuable resources. When an outgroup poses a threat to one's physical welfare, individuals are likely to experience fear prompting an avoidance reaction and self-protective behaviours. On the other hand, when an outgroup poses a threat to economic resources individuals are more likely to experience anger, instigating confrontational behaviour directed at removing the obstacle to desired outcomes. The emotional response is functional, because it elicits behaviour meant to deal with the problem and the threat at hand.

Evidence consistent with this model has shown that threat-emotion profiles evoked by groups predict policy attitudes (Cottrell, et al., 2010) and behavioural intentions towards them (Johnston \& Glasford, 2014). Kamans and colleagues (2011) showed that priming a safety threat concerning a possible military attack made by Iran on Western Europe led participants to react with fear and avoidance behavioural tendencies. Alternatively, when participants read about plans for Iran to restrict oil exports to Western Europe, they reacted with anger and intentions to confront the outgroup. Similarly, following the 9/11 attacks, Stitka et al. (2006) showed that anger predicted support for expanding the war beyond Afghanistan, while fear predicted support for deporting Arab Americans, Muslims and first-generation immigrants.

The present research tested a novel threat-matching hypothesis which predicts that the emotional processes underlying intergroup contact effects will depend on the specific threat posed by the outgroup. Prior research has established that intergroup contact reduces general prejudice, at least in part, by reducing threat perceptions (for meta-analysis, see Aberson, 2019). The implication of the sociofunctional approach is that rather than reducing global negative feelings emerging from a global threat, intergroup contact processes will be nuanced and determined by the salient threat posed by the outgroup. At the time this study was conducted the virus, originating in China, posed a salient welfare threat. The threat from 
COVID-19 was already impacting attitudes and behaviour towards Chinese people, with an increase in unwelcoming sentiment and discriminatory behaviour towards Chinese people being reported, including Chinese people being banned from restaurants and hotels (Chung \& Li, 2020; Schild et al., 2020). Such acts reflect an avoidant reaction towards presumed carriers of the disease but are ultimately discriminatory, conflating the pandemic with ethnic and national identity. We predicted that past experience of positive contact with Chinese people would be associated with a reduction in negative intergroup emotions and reduction in support for anti-Chinese policies. Negative contact meanwhile was expected to be associated with an increase in negative reactions to Chinese people. Importantly, if our threat-matching hypothesis is supported, fear will serve as the functional emotion that mediates the association between past intergroup contact and policy preferences.

\section{Method}

\section{Participants}

On $21^{\text {st }}$ February 2020, 351 participants from the UK were recruited from an online participant panel, Prolific. Although samples recruited through these platforms are not fully representative, they typically include respondents who vary more broadly in age, level of education, political ideology, and geographic distribution than those recruited from undergraduate student populations (Huff \& Tingley, 2015; Levay et al., 2016). The data was analysed using structural equational modelling (SEM), and sample size was determined using Soper's (2019) online tool. We specified an effect size of $d=.20$, and a desired power of $80 \%$. With fifteen indicators, a minimum sample size of 288 was recommended. Eleven participants were excluded because they described their ethnicity as Asian. The final sample consisted of 340 participants (202 female) aged between 18 to $75(M=38.96, S D=12.38)$. The majority of the participants were White (93.5\%). 


\section{Procedure}

We report how we determined our sample size, all data exclusions (if any), all manipulations, and all measures in the study. The study was advertised as a survey exploring opinions about COVID-19. The order of all scales was counterbalanced. Participants indicated their attitudes towards Chinese people as well as a range of other social groups (American, Polish, British, Irish and Spanish) with widely used attitude thermometers ranging from 0 to 10 (Haddock et al., 1993). The attitude thermometers represented a measure of generalized prejudice. Scores were reverse coded such that higher scores reflected higher prejudice.

To assess discrete intergroup emotions participants were asked to indicate the extent to which they felt a variety of emotions towards Chinese people ('angry', 'infuriated', 'fearful', 'outraged', 'disgusted', 'afraid', 'repulsed', 'sickened', 'grossed out') using 7-point Likert scales ( $1=$ not at all, 7 = very much; Giner-Sorolla \& Russell, 2019). The emotion items were subjected to a principal components analysis which revealed the presence of only one component with an eigenvalue exceeding 1 explaining $75.5 \%$ of variance. It is not uncommon to have empirical difficulties in separating emotional items for analyses (Neuberg \& Cottrell, 2002). As the discrete emotion constructs of fear and anger were theoretically important to our analysis, the decision was taken to proceed with the analysis using single items variables "angry" and "fearful". 1

To measure prior intergroup contact, participants indicated how often they have had positive/good, and negative/bad contact with Chinese people on seven-point scales $(1=$ never, 7 = very often; Barlow et al., 2012). Such single-item measures of positive and negative intergroup contact are commonly used and correlate strongly with longer measures (Hayward et al., 2018). 
Perceived threat posed by Chinese people was measured with three items adapted from Cottrell et al., (2010). The items focused on threat to physical welfare, specifically "Chinese people threaten the health of British people like me", "Chinese people increase the risk of physical illness to British people like me" and "Chinese people increase the risk of British people like me contracting an infectious disease" $(1=$ strongly disagree, $7=$ strongly agree, $\alpha=.96)$.

Finally, we asked participants to what extent they supported nine policy measures the UK government could take to stop the spread of coronavirus (see Supporting Information). Five items embedded in this scale concerned measures targeted at restricting the activities of Chinese people in the UK, including "Enforce a quarantine of all Chinese nationals in the UK" and "Close all Chinese restaurants" $(1=$ strongly oppose, $7=$ strongly support, $\alpha=.70)$. Four items concerned general restrictions to contain the virus, including, "Ban large public gatherings, such as football matches and concerts" and "Close public transportation in UK cities where coronavirus has been reported" $(\alpha=.67)^{2}$. To conclude the study participants provided demographic information and were thanked and debriefed.

\section{Results}

First, we examined the correlations amongst all variables. These are presented in Table 1 along with descriptive statistics. Positive contact had a significant negative relationship with Chinese prejudice, welfare threat, fear, anger, and support for Chinese restriction policies. Negative contact, meanwhile, was significantly positively related to prejudice, welfare threat, fear, anger and support for Chinese restriction policies. 
A one-way repeated measures ANOVA revealed a significant difference in prejudice towards the different outgroup targets as measured with the attitude thermometers, $F(3.92$, $1319.09)=33.73, p<.001$, partial $\eta 2=.09$. Using post-hoc pairwise comparisons we compared prejudice towards Chinese people to each of the five other national groups with Bonferroni adjustments for multiple comparisons (see Table 2). Results revealed that prejudice was significantly higher towards Chinese people than any other group at the time the study was conducted.

\section{[INSERT TABLE 2 ABOUT HERE]}

To test the affect-matching hypothesis, regression analyses were conducted to compare the strength of positive and negative contact effects on fear and anger. Results showed that positive and negative contact were both significant independent predictors of fear and anger towards Chinese people (see Table 3). A comparison of absolute standardized regression coefficients using the equation $\mathrm{z}=b^{1}-b^{2} / S E(b 1-\mathrm{b} 2)$ as per Barlow et al., (2019) showed that negative contact was a significantly stronger predictor of increased anger than positive contact was of reduced anger, $z=5.040, p<.001$. The difference in strength between the negative and positive contact associations with fear did not reach statistical significance, $z=.582, p=.560$. Partial support for affect-matching is therefore obtained.

\section{[INSERT TABLE 3 ABOUT HERE]}

We tested our threat-matching mediational model using SEM analysis with latent variables. The analysis was conducted using the Lavaan package (Rosseel, 2012) within R (R Core Team, 2018). The latent factor of support for Chinese restriction polices was indicated 
by five items and the general restriction policies was indicated by four items. Positive and negative contact and anger and fear were included as manifest indicators. Anger and fear were not normally distributed and so robust maximum likelihood estimation was deployed. The measurement model (reported in supporting information) showed an acceptable fit to the data, robust $\chi^{2}(26)=91.524, p<.001, \chi^{2} / \mathrm{df}$ ratio $=3.52$, robust $\mathrm{RMSEA}=.086[90 \% \mathrm{CI}$ $0.052-0.079], \mathrm{SRMR}=.046$, robust $\mathrm{CFI}=.939$. In the full structural model, we specified a parallel mediation model in which positive contact $\left(\mathrm{X}_{1}\right)$ and negative contact $\left(\mathrm{X}_{2}\right)$ predicted perceptions of fear $\left(\mathrm{M}_{1}\right)$ and anger $\left(\mathrm{M}_{2}\right)$ with support for Chinese restriction policies $\left(\mathrm{Y}_{1}\right)$ and general restriction polices $\left(\mathrm{Y}_{2}\right)$ as the outcome variables. The direct paths from positive and negative contact to policy support were also included. Fear and anger were allowed to correlate, as were the Chinese restriction polices and general restriction policies.

Figure 1 reports the results of this model which resulted in good model fit, robust $\chi^{2}$ $(54)=134.90, p<.001, \chi^{2} / \mathrm{df}$ ratio $=2.50$, Robust $\mathrm{RMSEA}=.065$ [90\% CI $\left.0.52-0.079\right]$, SRMR $=.046$, Robust CFI $=.939, N=340$. Tests of the indirect effects indicated that both positive and negative contact has a significant indirect effect on support for Chinese restriction policies via fear (positive contact, $b=-.094, \mathrm{CI}=-.124,-.033$; negative contact $b$ $=.111, \mathrm{CI}=.064, .206)$. The indirect effect of contact on support for Chinese restriction policies via anger were also significant though smaller in magnitude (positive contact $b=$ $.030, \mathrm{CI}=-.018,-.001$; negative contact $b=.096, \mathrm{CI}=.007, .080)$. The direct effect of negative contact on Chinese restriction policies were non-significant when the indirect paths were included. However, the direct effects of positive contact on Chinese restriction policies remained significant when the emotion variables were introduced to the model. The direct effects of positive $(b=-.058[-.057, .021])$ and negative contact $(b=-.004[-.113, .123])$ on support for general restriction policies were non-significant demonstrating that intergroup 
processes are only relevant to predicting support for discriminatory Chinese restriction policies, and not measures to contain the spread of the virus generally.

\section{[INSERT FIGURE 1 ABOUT HERE]}

We formally tested the null hypothesis that the indirect effects on intergroup contact on Chinese restriction policies via fear and anger are equal to each other by specifying contrasts in Lavaan to compare the indirect effects. The results revealed that the indirect effect of positive contact on Chinese restriction polices via fear was significantly stronger than the indirect effect of positive contact via anger $(b=-.064, \mathrm{CI}=-.114,-.025)$. The indirect effect of negative contact on Chinese restriction polices via fear was also significantly stronger than the indirect effect of negative contact via anger $(b=.016, \mathrm{CI}=$ $.011, .171)$. In other words, while both fear and anger significantly mediate the relationship between different types of intergroup contact and support for discriminatory policies to restrict Chinese people in the context of a salient welfare threat, fear is the stronger emotional process underlying these effects.

\section{General Discussion}

The present research investigated how past experience of intergroup contact with Chinese people predicted discrete intergroup emotions in the context of the COVID-19 crisis; and how these in turn predicted support for anti-Chinese restrictions. While positive contact was associated with lower support for discriminatory Chinese restrictions, negative contact was associated with increased policy support. In line with our threat-matching hypothesis, these effects were more strongly driven by fear than by anger. The present findings illustrate how a novel integration of intergroup contact theory with intergroup emotion approaches can 
provide a more nuanced understanding of how specific threats and emotions drive intergroup contact effects.

The sociofunctional threat tradition has generally assumed threats posed by groups are relatively stable group-level perceptions. The intergroup emotions literature, which is built upon cognitive appraisal theories of emotion, however, has long assumed that specific manifestations of prejudicial emotions are context dependent (Mackie \& Smith, 2018; Scherer, 2009; Smith \& Mackie, 2008) and experimental studies have shown that priming different threats elicited by the same outgroup can produce distinct emotional and behavioural responses (e.g. Kamans et al., 2011). The present findings recognise that threat appraisals can be contextual and responsive to events such as geopolitical events, acts of violence, or a pandemic which can change which intergroup threats are most salient or relevant in the situation. Importantly, then, we may not necessarily expect the results we observe here - where anti-Chinese discrimination is driven primarily by fear - to generalize beyond the moment in time and cultural context in which they were found. It is very possible that the salience of the welfare threat posed by Chinese people waned as the virus became severe in other part of Europe, and then the UK. Indeed, when the financial consequences of COVID-19 become more salient than the health threat, a similar study could focus on Chinese people as a source of economic threat where we would expect anger to play a more dominant role in driving contact effects and predicting retaliatory behaviours.

Our research comprises a cross-sectional survey and this naturally limits any capacity to make causal claims. Our threat-matching hypothesis concerns the emotional processes driving contact effects and while an indirect effect is statistical evidence consistent with causation but is insufficient to establish causation. It should also be noted that the size of the associations between our emotion variables and policy support outcomes are larger than the association between intergroup contact and these outcomes. This is perhaps not surprising 
given the novel nature of these outcome variables for contact research. Importantly, this study moved beyond the prejudice-as-general-attitude approach and shows that intergroup contact plays an important role predicting functionally distinct emotional and behavioural responses in response to salient threats.

Future tests of our threat-matching hypothesis should also seek to incorporate multiple outgroups with different threat-emotion profiles. The reliability of the contactprejudice association means that researchers largely overlook the unique characteristics that define group membership when selecting outgroups for research. However, this generalized approach ignores the fact that individuals may react differently in terms of both affect and behaviour towards different outgroups and in different intergroup contexts. The implication of our findings is that the processes and outcomes of intergroup contact may vary as a function of the target outgroup and the threat context. Simultaneously assessing contact with multiple groups and measuring discrete threats, emotions, and behaviours will be critical to building insight into the complexity of intergroup contact effects.

We also found partial support for the affect matching hypothesis (Barlow et al., 2019) with negative contact being more strongly related to increased anger than positive contact was of reduced anger. The association between negative contact and fear was also trending larger than the association between positive contact and fear but the difference did not reach statistical significance. Such results further reinforce the importance of examining discrete intergroup emotions, suggesting that the consequences of intergroup contact may depend both on the type of contact (affect-matching), and specific threat posed by the outgroup (threat-matching).

Our study focused on a brief moment in the COVID-19 timeline. The epidemiological situation is constantly changing and worldwide people are adopting avoidance and social distancing measures as "a new normal" to fight the spread of the virus. All of the general 
restriction policies in the current study received low support from our participants in February, only to be enacted three weeks later by the UK Government. Avoidance of others has been seen as virtuous since this time. Necessarily, this means a reduction in social contact not just with Chinese people, but with other outgroups as well as ingroups. Future work will need to explore how intergroup contact is rebuilt as threat recede. It remains to be seen whether long-term recovery from this pandemic will promote a spirit of global cooperation or suspicion, threat and xenophobia. Past contact experiences are likely to predict which path an individual chooses.

\section{Conclusion}

In summary, our results suggest that by investigating the structural relationship between positive and negative contact, specific intergroup emotions and threats, we are ultimately able to identify the finely grained mechanism(s) responsible for contact effects, thus simultaneously achieving a differentiated and an integrated view of the process and of the outcome of intergroup contact. The focus on intergroup emotions and behavioural tendencies is a welcome complement to studies predicting attitudes from contact, and should remain fruitful even in a future without a global emergency. 


\section{References}

Aberson, C. L. (2019). Indirect effects of threat on the contact-prejudice relationship: A meta-analysis. Social Psychology, 50(2), 105-126. https://doi.org/10.1027/1864$9335 / \mathrm{a} 000364$

Akaike, H. (1974). A New Look at the Statistical Model Identification. IEEE Transactions on Automatic Control, 19(6), 716-723. https://doi.org/10.1109/TAC.1974.1100705

Allport, G. W. (1954). The nature of prejudice. Retrieved from http://www.worldcat.org/title/nature-of-prejudice/oclc/204034

Aubé, B., \& Ric, F. (2019). The sociofunctional model of prejudice: Questioning the role of emotions in the threat-behavior link. International Review of Social Psychology, 32(1), 1. https://doi.org/10.5334/irsp.169

Barlow, F. K., Hornsey, M. J., Hayward, L. E., Houkamau, C. A., Kang, J., Milojev, P., \& Sibley, C. G. (2019). Why do we hold mixed emotions about racial out-groups? A case for affect matching. Psychological Science, 095679761984426. https://doi.org/10.1177/0956797619844269

Barlow, F. K., Paolini, S., Pedersen, A., Hornsey, M. J., Radke, H. R. M., Harwood, J., ... Sibley, C. G. (2012). The contact caveat: Negative contact predicts increased prejudice more than positive contact predicts reduced prejudice. Personality and Social Psychology Bulletin, 38(12), 1629-1643. https://doi.org/10.1177/0146167212457953

Chung, R. Y. N., \& Li, M. M. (2020, February 29). Anti-Chinese sentiment during the 2019nCoV outbreak. The Lancet, Vol. 395, pp. 686-687. https://doi.org/10.1016/S0140$6736(20) 30358-5$

Cottrell, C. A., \& Neuberg, S. L. (2005). Different emotional reactions to different groups: A sociofunctional threat-based approach to "prejudice." Journal of Personality and Soclal Psychology, 88(5), 770-789. https://doi.org/10.1037/0022-3514.88.5.770 
Cottrell, C. A., Richards, D. A. R., \& Nichols, A. L. (2010). Predicting policy attitudes from general prejudice versus specific intergroup emotions. Journal of Experimental Social Psychology, 46(2), 247-254. https://doi.org/10.1016/j.jesp.2009.10.008

Davies, K., Tropp, L. R., Aron, A., Pettigrew, T. F., \& Wright, S. C. (2011). Cross-group friendships and intergroup attitudes: A meta-analytic review. Personality and Social Psychology Review, 15(4), 332-351. https://doi.org/10.1177/1088868311411103

Fiske, S. T., Cuddy, A. J. ., Glick, P., \& Xu, J. (2002). A model of (often mixed) stereotype content: competence and warmth respectively follow from perceived status and competition. Journal of Personality and Social Psychology, 82(6), 878-902. https://doi.org/10.1037/0022-3514.82.6.878

Hayward, L. E., Tropp, L. R., Hornsey, M. J., \& Barlow, F. K. (2018). How negative contact and positive contact with Whites predict collective action among racial and ethnic minorities. British Journal of Social Psychology, 57(1), 1-20. https://doi.org/10.1111/bjso.12220

Hodson, G., Choma, B. L., Boisvert, J., Hafer, C. L., MacInnis, C. C., \& Costello, K. (2013). The role of intergroup disgust in predicting negative outgroup evaluations. Journal of Experimental Social Psychology, 49(2), 195-205.

https://doi.org/10.1016/j.jesp.2012.11.002

Huff, C., \& Tingley, D. (2015). “Who are these people?” Evaluating the demographic characteristics and political preferences of MTurk survey respondents. Research \& Politics, 2(3), 2053168015604648. https://doi.org/10.1177/2053168015604648

Johnston, B. M., \& Glasford, D. E. (2014). A threat-emotion profile approach to explaining active versus passive harm in intergroup relations. Social Psychology, 45(5), 399-407. https://doi.org/10.1027/1864-9335/a000199

Kamans, E., Otten, S., \& Gordijn, E. H. (2011). Power and threat in intergroup conflict: How 
emotional and behavioral responses depend on amount and content of threat. Group Processes and Intergroup Relations, Vol. 14, pp. 293-310. https://doi.org/10.1177/1368430210372525

Kauff, M., Asbrock, F., Wagner, U., Pettigrew, T. F., Hewstone, M., Schäfer, S. J., \& Christ, O. (2017). (Bad) feelings about meeting them? Episodic and chronic intergroup emotions associated with positive and negative intergroup contact as predictors of intergroup behavior. Frontiers in Psychology, 8, 1449.

https://doi.org/10.3389/fpsyg.2017.01449

Lazarus, R. S. (1991). Progress on a cognitive-motivational-relational theory of emotion. The American Psychologist, 46(8), 819-834. https://doi.org/10.1037/0003-066X.46.8.819

Lemmer, G., \& Wagner, U. (2015). Can we really reduce ethnic prejudice outside the lab? A meta-analysis of direct and indirect contact interventions. European Journal of Social Psychology, 45(2). https://doi.org/10.1002/ejsp.2079

Levay, K. E., Freese, J., \& Druckman, J. N. (2016). The demographic and political composition of Mechanical Turk samples. SAGE Open, 6(1), 2158244016636433. https://doi.org/10.1177/2158244016636433

Mackie, D. M., \& Smith, E. R. (2018). Intergroup emotions theory: Production, regulation, and modification of group-based emotions. In Advances in Experimental Social Psychology (Vol. 58, pp. 1-69). https://doi.org/10.1016/bs.aesp.2018.03.001

Meleady, R., Seger, C. R., \& Vermue, M. (2017). Examining the role of positive and negative intergroup contact and anti-immigrant prejudice in Brexit. British Journal of Social Psychology, 56(4), 799. Retrieved from http://search.ebscohost.com/login.aspx?direct=true $\& d b=e d b \& A N=126530921 \&$ site $=e d s$ -live \&scope $=$ site

Neuberg, S., \& Cottrell, C. (2002). Intergroup emotions: A biocultural approach. In D. M. 
Mackie \& E. R. Smith (Eds.), From prejudice to intergroup emotions : differentiated reactions to social groups (pp. 265-283). New York: Psychology Press.

Paterlini, M. (2020). “Closing borders is ridiculous": the epidemiologist behind Sweden's controversial coronavirus strategy. Nature. https://doi.org/10.1038/d41586-020-01098-x

Pettigrew, T. F., \& Tropp, L. R. (2006). A meta-analytic test of intergroup contact theory. Journal of Personality and Social Psychology, 90(5), 751-783. https://doi.org/10.1037/0022-3514.90.5.751

Pettigrew, T. F., \& Tropp, L. R. (2011). When groups meet: The dynamics of intergroup contact. In When Groups Meet: The Dynamics of Intergroup Contact. https://doi.org/10.4324/9780203826461

Quigley, A. (2020). Coronavirus outbreak predicted to have an impact on financial markets and the global economy. Retrieved from https://www.ipsos.com/ipsos-mori/enuk/coronavirus-outbreak-predicted-have-impact-financial-markets-and-global-economy

R Core Team. (2018). A language and enviroment for statistical computing (p. URL https://www.R-project.org/). p. URL https://www.R-project.org/. https://doi.org/10.1126/science.1136800>.

Rosseel, Y. (2012). An R package for structural equation modeling and more. In Journal of Statistical Software. https://doi.org/10.18637/jss.v048.i02

Schild, L., Ling, C., Blackburn, J., Stringhini, G., Zhang, Y., \& Zannettou, S. (2020). “Go eat a bat, Chang!": An early look on the emergence of sinophobic behavior on web communities in the face of COVID-19. ArXiv.Org, (eprint). Retrieved from http://arxiv.org/abs/2004.04046

Seger, C. R., Banerji, I., Park, S. H., Smith, E. R., \& Mackie, D. M. (2017). Specific emotions as mediators of the effect of intergroup contact on prejudice: findings across multiple participant and target groups. Cognition and Emotion, 31(5), 923-936. 
https://doi.org/10.1080/02699931.2016.1182893

Skitka, L. J., Bauman, C. W., Aramovich, N. P., \& Morgan, G. S. (2006). Confrontational and preventative policy responses to terrorism: anger wants a fight and fear wants “Them” to go away. Basic and Applied Social Psychology, 28(4), 375-384. https://doi.org/10.1207/s15324834basp2804_11

Soper, D. S. (2019). A-priori sample size for structural equation models. Retrieved April 1, 2020, from Free Statistics Calculators website: http://www.danielsoper.com/statcalc Stark, T. H., Flache, A., \& Veenstra, R. (2013). Generalization of positive and negative attitudes toward individuals to outgroup attitudes. Personality and Social Psychology Bulletin, 39(5), 608-622. https://doi.org/10.1177/0146167213480890 WHO. (2020). Situation Report-32. 
Table 1: Descriptive statistics and correlations for all variables.

\begin{tabular}{|c|c|c|c|c|c|c|c|c|c|}
\hline Variables & $M$ & $S D$ & 1 & 2 & 3 & 4 & 5 & 6 & 7 \\
\hline 1. Positive contact & 3.95 & 1.68 & & & & & & & \\
\hline 2. Negative contact & 1.80 & 1.16 & -.044 & & & & & & \\
\hline 3. Chinese prejudice & 2.15 & 1.63 & $-.358 * *$ & $.378 * *$ & & & & & \\
\hline 4. Welfare threat & 1.59 & 1.22 & $-.212 * *$ & $.308 * *$ & $.553 * *$ & & & & \\
\hline 5. Fear & 2.86 & 1.36 & $-.212 * *$ & $.247 * *$ & $.457 * *$ & $.659 * *$ & & & \\
\hline 6. Anger & 3.98 & 1.46 & $-.164 * *$ & $.467 * *$ & $.490 * *$ & $.572 * *$ & $.555^{* *}$ & & \\
\hline 7. Support for general restriction policies & 3.81 & 2.43 & $-.260 * *$ & $.201 * *$ & $.407 * *$ & $.579 * *$ & $.540^{* *}$ & $.436^{* *}$ & \\
\hline 8. Support for Chinese restriction policies & 2.42 & 1.52 & $-.107 *$ & .053 & $.170^{* *}$ & $.333 * *$ & $.304 * *$ & $.222 * *$ & $.538 * *$ \\
\hline
\end{tabular}

Note. ${ }^{*} p<.05, * * p<.001$ 
Table 2: Descriptive statistics and pairwise comparisons for prejudice attitudes held toward Chinese people compared to five other national groups.

\begin{tabular}{|c|c|c|c|c|c|c|}
\hline \multirow[b]{2}{*}{ Nationality } & \multirow[b]{2}{*}{$M$} & \multirow[b]{2}{*}{$S D$} & \multirow[b]{2}{*}{ Mean Diff } & \multirow[b]{2}{*}{$p$} & \multicolumn{2}{|c|}{$\begin{array}{c}\text { 95\% Confidence } \\
\text { Intervals }\end{array}$} \\
\hline & & & & & LB & UB \\
\hline Chinese & 3.78 & 2.41 & & & & \\
\hline Polish & 2.79 & 2.19 & .991 & $<.001$ & .67 & 1.31 \\
\hline American & 3.31 & 2.27 & .475 & $<.001$ & .12 & .83 \\
\hline British & 2.66 & 2.06 & 1.12 & $<.001$ & .68 & 1.56 \\
\hline Spanish & 2.88 & 1.93 & .095 & $<.001$ & .61 & 1.20 \\
\hline Irish & 2.43 & 1.86 & 1.35 & $<.001$ & 1.02 & 1.69 \\
\hline
\end{tabular}


Table 3: Regression models testing the affect-matching hypothesis by examining the association between positive and negative intergroup contact with Chinese people and fear and anger towards this group

\begin{tabular}{|c|c|c|c|c|c|c|c|c|}
\hline \multirow[b]{2}{*}{ Model } & & \multirow[t]{2}{*}{$B$} & \multicolumn{2}{|c|}{$95 \% \mathrm{CI}$ for $B$} & \multirow[t]{2}{*}{$S E B$} & \multirow[t]{2}{*}{$B$} & \multirow[t]{2}{*}{$R^{2}$} & \multirow[t]{2}{*}{$F$} \\
\hline & & & $\mathrm{LL}$ & UL & & & & \\
\hline Fear & & & & & & & .101 & $19.034^{* * *}$ \\
\hline & Constant & $2.318^{* * *}$ & 1.814 & 2.823 & .257 & & & \\
\hline & Positive Contact & $-.195^{* * *}$ & -.294 & -.097 & .050 & -.201 & & \\
\hline & Negative Contact & $.335^{* * *}$ & .192 & .478 & .073 & .238 & & \\
\hline Anger & & & & & & & .488 & $52.745^{* * *}$ \\
\hline & Constant & $1.132^{* * *}$ & .784 & 1.479 & .177 & & & \\
\hline & Positive Contact & $-.104^{*}$ & -.172 & -.037 & .035 & -.144 & & \\
\hline & Negative Contact & $.484^{* * *}$ & .386 & .582 & .050 & .460 & & \\
\hline
\end{tabular}

Note. ${ }^{*} p<.05, * * p<.01 ; * * * p<.001$ 


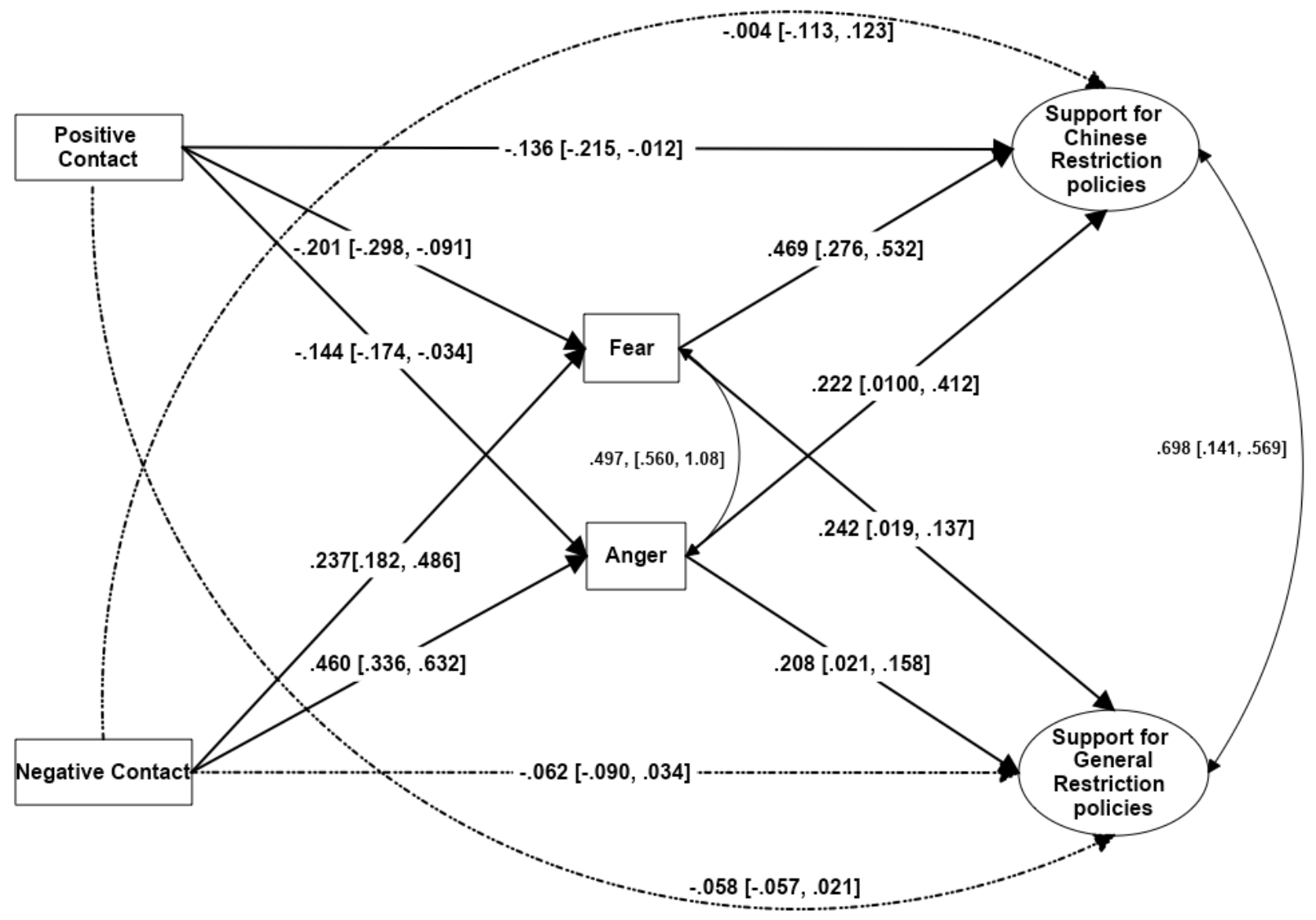

Figure 1: Empirical fit of structural equation model of the associations between contact, emotion and support for Chinese restriction policies and support for general restriction policies. All paths except the dash lines are significant. Coefficients are standardized, $95 \%$ Confidence Intervals are reported in square brackets. Note: To simplify presentation, the measurement model is shown in the Supporting Information. 


\section{Notes}

${ }^{1}$ The sociofunctional model identifies a total of five distinct threat-emotion profiles, including a contamination-disgust-rejection profile which suggests that outgroups elicit disgust when they are perceived to be a source of physical or moral contamination (Cottrell \& Neuberg, 2005). Evidence for this profile is mixed, with studies suggesting that both disgust and fear result from contamination threat (Aubé \& Ric, 2019; Johnston \& Glasford, 2014) According to appraisal theories of emotion (Lazarus, 1991) if an intergroup encounter is appraised as posing danger and the person believes they may not survive the uncertain or existential threat before them, anxiety or fright may be a more likely emotional reaction than disgust to prevent contamination. Others have conceptualised intergroup disgust in terms of social contaminants (e.g. ideas, values, Hodson et al., 2013). For these reasons we choose to focus on the role of fear, rather than disgust in the context of the threat of COVID-19 infection. If we include fear, anger and disgust as parallel mediators in our model, the indirect effect of positive and negative contact on Chinese restriction policies via fear remains significant but the indirect effects of anger and disgust are non-significant. This alternative model is reported in the supplementary materials.

\footnotetext{
${ }^{2} \mathrm{We}$ also measured four further policy items. Two items referred to financial aid and building temporary hospitals, which did not fit our "restrictive" policy measure and two items referred to general (not Chinese) prejudice, so these were not included in our analyses. For exploratory purposes we also measured risk-taking propensity and general Covid-19 anxiety. These measures are not analysed here.
} 